\title{
Article \\ Bioprinting of a Zonal-Specific Cell Density Scaffold: A Biomimetic Approach for Cartilage Tissue Engineering
}

\author{
Angeliki Dimaraki ${ }^{1,+}+$, Pedro J. Díaz-Payno ${ }^{1,2,+} \mathbb{C}$, Michelle Minneboo ${ }^{1}$, Mahdiyeh Nouri-Goushki ${ }^{1}{ }^{\circledR}$, \\ Maryam Hosseini ${ }^{1,3}{ }^{(D}$, Nicole Kops ${ }^{2}$, Roberto Narcisi ${ }^{2}{ }^{1}$, Mohammad J. Mirzaali ${ }^{1}{ }^{\circ}$, \\ Gerjo J. V. M. van Osch ${ }^{1,2,4} \mathbb{C}^{-}$, Lidy E. Fratila-Apachitei ${ }^{1}\left[\right.$ and Amir A. Zadpoor ${ }^{1, * \mathbb{C}}$
}

1 Department of Biomechanical Engineering, Faculty of Mechanical, Maritime and Materials Engineering, Delft University of Technology, 2628 CD Delft, The Netherlands; a.dimaraki@student.tudelft.nl (A.D.); p.j.diazpayno@tudelft.nl (P.J.D.-P.); M.B.Minneboo@tudelft.nl (M.M.); M.NouriGoushki@tudelft.nl (M.N.-G.); M.Hosseini@tudelft.nl (M.H.); M.J.Mirzaali@tudelft.nl (M.J.M.); G.J.V.M.VanOsch@tudelft.nl (G.J.V.M.v.O.); E.L.Fratila-Apachitei@tudelft.nl (L.E.F.-A.)

2 Department of Orthopedics and Sports Medicine, Erasmus MC University Medical Center, 3015 GD Rotterdam, The Netherlands; n.kops@erasmusmc.nl (N.K.); r.narcisi@erasmusmc.nl (R.N.)

3 Department of Chemical Engineering, Faculty of Engineering, Azarbaijan Shahid Madani University, Tabriz 53714-161, Iran

4 Department of Otorhinolaryngology, Erasmus MC University Medical Center, 3015 GD Rotterdam, The Netherlands

Citation: Dimaraki, A.; Díaz-Payno, P.J.; Minneboo, M.; Nouri-Goushki, M.; Hosseini, M.; Kops, N.; Narcisi,

R.; Mirzaali, M.J.; van Osch, G.J.V.M.; Fratila-Apachitei, L.E.; et al. Bioprinting of a Zonal-Specific Cell Density Scaffold: A Biomimetic Approach for Cartilage Tissue Engineering. Appl. Sci. 2021, 11, 7821. https://doi.org/

10.3390/app11177821

Academic Editor: Rossella Bedini

Received: 20 July 2021

Accepted: 20 August 2021

Published: 25 August 2021

Publisher's Note: MDPI stays neutral with regard to jurisdictional claims in published maps and institutional affiliations.

Copyright: (c) 2021 by the authors. Licensee MDPI, Basel, Switzerland. This article is an open access article distributed under the terms and conditions of the Creative Commons Attribution (CC BY) license (https:// creativecommons.org/licenses/by/ $4.0 /)$.
* Correspondence: A.A.Zadpoor@tudelft.nl

$\dagger$ These authors contributed equally.

Abstract: The treatment of articular cartilage defects remains a significant clinical challenge. This is partially due to current tissue engineering strategies failing to recapitulate native organization. Articular cartilage is a graded tissue with three layers exhibiting different cell densities: the superficial zone having the highest density and the deep zone having the lowest density. However, the introduction of cell gradients for cartilage tissue engineering, which could promote a more biomimetic environment, has not been widely explored. Here, we aimed to bioprint a scaffold with different zonal cell densities to mimic the organization of articular cartilage. The scaffold was bioprinted using an alginate-based bioink containing human articular chondrocytes. The scaffold design included three cell densities, one per zone: $20 \times 10^{6}$ (superficial), $10 \times 10^{6}$ (middle), and $5 \times 10^{6}$ (deep) cells $/ \mathrm{mL}$. The scaffold was cultured in a chondrogenic medium for 25 days and analyzed by live/dead assay and histology. The live/dead analysis showed the ability to generate a zonal cell density with high viability. Histological analysis revealed a smooth transition between the zones in terms of cell distribution and a higher sulphated glycosaminoglycan deposition in the highest cell density zone. These findings pave the way toward bioprinting complex zonal cartilage scaffolds as single units, thereby advancing the translation of cartilage tissue engineering into clinical practice.

Keywords: bioprinting; biofabrication; tissue engineering; articular cartilage; human chondrocytes; cell density; cell gradient

\section{Introduction}

Articular cartilage (AC) may be damaged due to aging, disease, or trauma. AC has a limited regenerative capacity that has been attributed to the lack of innervation and the avascular nature of the tissue [1]. AC defects may progress to the subchondral bone to create an osteochondral defect. If left untreated, such defects can potentially lead to the development of osteoarthritis [2,3], a cartilage-degenerating disease affecting over 300 million worldwide and representing a burden on the healthcare systems globally [4,5]. The treatment of AC defects often results in a fibrocartilage tissue with poor long-term outcomes [6], thus presenting a significant clinical challenge. This is partially because the current regenerative and tissue engineering strategies fail to recapitulate the native 
organization of the AC tissue. AC is a graded tissue that has three main zones: superficial, middle, and deep. These zones are associated with differences in matrix composition, matrix structural organization, and cell number, which result in gradients with complex physical, mechanical, and biological properties [7]. In adult healthy human articular cartilage, the superficial zone is characterized by thickly packed collagen type II fibers, a high tensile strength, and a high cell density, while the deep zone is characterized by a high sulfated glycosaminoglycan (sGAG) content, high compressive strength, and a low cell density as compared to the other layers [8].

Different biofabrication strategies, such as bioprinting, have been exploited to recapitulate few of the gradients connecting the three zones [9]. Graded scaffolds aim to mimic the highly organized native tissue. Several studies have explored the fabrication of multilayered constructs exhibiting differences in biological [10] or chemical composition [11-14] and physical or mechanical properties [15-17]. Different gradient strategies have also been combined to tailor physical (stiffness) and biochemical (growth factor) gradients that better control stem-cell behavior [18].

To the best of our knowledge, there has been only one study introducing a cell density gradient in a bioprinted construct [19], where swine articular cartilage-derived constructs with different density gradients of rabbit chondrocytes were compared to constructs with equivalent homogeneous cell distribution. In the study, gene expression and sGAG deposition were quantified for the overall constructs. However, limited information was presented regarding the extracellular matrix (ECM) that was deposited by the cells at different densities in each zone. Therefore, further research is warranted to characterize the cell-derived tissue deposition in each of the zones within a graded construct, especially using human material.

The aims of this paper were (i) to design and fabricate scaffolds with three-zone cell density using bioprinting with an alginate-based bioink containing human articular chondrocytes and a poly- $\varepsilon$-caprolactone (PCL) support structure, (ii) to characterize the cell viability and cell gradient stability overtime, and (iii) to evaluate the time-dependent deposition of ECM by the cells embedded in the scaffolds. To achieve the cell density gradient, the design of the scaffolds included three zones with three different cell densities. The different zones aimed to mimic both the dimensions and cell density of the superficial, middle, and deep zones as seen in the native structure of articular cartilage.

\section{Materials and Methods}

\subsection{Scaffold Design}

Solidworks was used to design a standard tessellation language (.STL) file of scaffold solid form that incorporated both the PCL outer skeleton and the cell-embedded bioink part. The PCL skeleton design was composed of a square base of $8 \times 8 \mathrm{~mm}^{2}$ with a thickness of two layers $(0.4 \mathrm{~mm})$ and four vertical pillars at the corners with a height of $3 \mathrm{~mm}$. The scaffold was designed as a $7.2 \mathrm{~mm} \times 7.2 \mathrm{~mm} \times 3 \mathrm{~mm}$ cube. The designed STL file was then processed in Slic3r [20] to generate the gcode file used by the bioprinter (BIO-X bioprinter, Cellink, Sweden). Briefly, the parameters used in Slic3r were as follows: infill pattern, rectilinear; infill density, 100\% for PCL frame design and 10\% for scaffold design; infill angle, $90^{\circ}$; solid infill threshold area, 10; layer height, $0.2 \mathrm{~mm}$; nozzle diameter, $0.2 \mathrm{~mm}$. Two types of scaffolds were designed: a scaffold corresponding to a homogeneous cell density with one zone of 15 layers and a scaffold with three different zones corresponding to the three different cell densities. The dimensions of the zones were chosen to mimic the dimensions of the three different zones in the human articular cartilage. The top zone had a thickness of three layers $(0.6 \mathrm{~mm})$, the middle zone had a thickness of seven layers $(1.4 \mathrm{~mm})$, and the bottom zone had a thickness of five layers $(1 \mathrm{~mm})$, resulting in a total of 15 layers per scaffold. 


\subsection{Bioink Formulation}

An alginate-based biomaterial (IK1020000303, Cellink Bioink, Cellink, Sweden) was mixed with human chondrocytes according to the manufacturer's instructions to create the bioink. Briefly, human articular chondrocytes isolated from hyaline cartilage in the knee and expanded to the second passage were purchased from Lonza (NHAC-kn, Lonza Bioscience, Breda, The Netherlands). The cells were expanded until the third passage in chondrocyte growth medium (CC-3216, Lonza Bioscience, Breda, The Netherlands) according to the manufacturer's instructions, in an incubator at $37^{\circ} \mathrm{C}, 5 \% \mathrm{CO}_{2}$, and $90 \%$ humidity. The cells were trypsinized when confluency was reached, counted, and re-suspended in a growth medium. The hydrogel was taken up from the stock cartridge by a syringe and was mixed gently 10:1 with the cell suspension using a sterile female-female luer lock, and a second syringe was used to homogenize the cells in the bioink. The mixture was transferred to a new cartridge for bioprinting. According to the study by Hunziker et al., the total cell density within the human articular cartilage of a medial femoral condyle is $10 \times 10^{3} \mathrm{cell} / \mathrm{mm}^{3}$ [21]. Therefore, the homogeneous scaffold was given a biomimetic total cell density of $10 \times 10^{6} \mathrm{cell} / \mathrm{mL}$. Hunziker et al. also described the different cell densities in the different zones of articular cartilage in which it was established that the cell densities corresponding to the superficial, middle, and deeps zones are $24 \pm 3 \times 10^{3}$ cells $/ \mathrm{mm}^{3}$, $10 \pm 0.5 \times 10^{3}$ cells $/ \mathrm{mm}^{3}$, and $7 \pm 0.5 \times 10^{3}$ cells $/ \mathrm{mm}^{3}$, respectively [21]. The gradient scaffold was given a similar biomimetic cell density corresponding to each zone of the articular cartilage: superficial (top), middle (middle) and deep (bottom) zones. The top, middle, and bottom zones were designed to respectively have $20 \times 10^{6}$ cells $/ \mathrm{mL}$, $10 \times 10^{6}$ cells $/ \mathrm{mL}$, and $5 \times 10^{6}$ cells $/ \mathrm{mL}$, respectively (Figure 1 ).
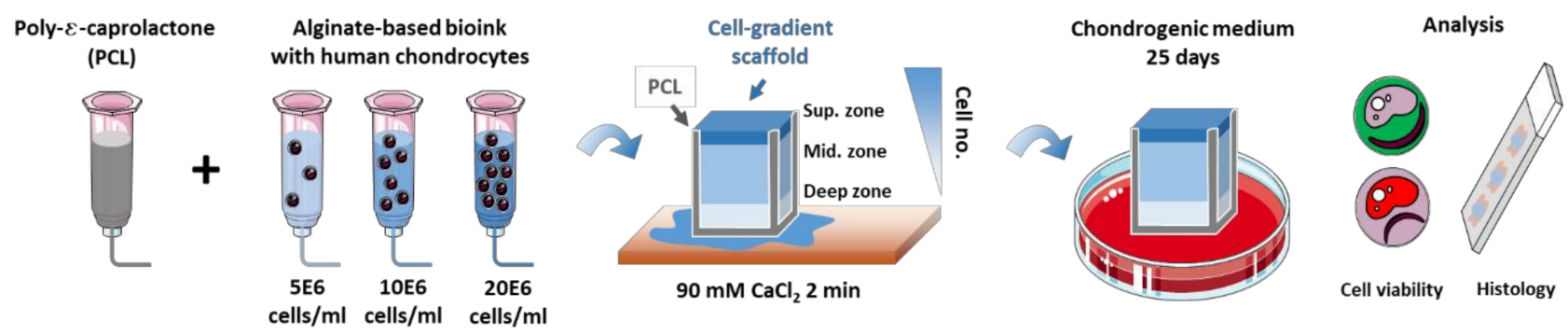

Figure 1. A schematic representation of the fabrication methodology and the in vitro setup of the study. A PCL-reinforced alginate-based scaffold containing human chondrocytes was 3D bioprinted with different cell densities mimicking the cell gradient of the human articular cartilage zones. The scaffold was ionically crosslinked post bioprinting before supplementing with chondrogenic medium for 4 weeks. After in vitro culture, the samples were analyzed for cell viability and for matrix deposition through histological staining.

\subsection{Bioprinting}

The BIO-X bioprinter (Cellink, Sweden) was UV-sterilized and used inside a cell culture hood to ensure that the bioprinting process would run under sterile conditions. After sterilization, the gcode file was used to print the scaffold. Briefly, the printing surface, nozzle size, temperature, pressure, and speed of each print-head was selected through the bioprinter's interface. The selected parameters for each print-head are presented below (Table 1). Next, the three printheads were manually calibrated to the same spot in the printing surface to ensure a complete match when swapping printheads during the printing process for the different bioinks and biomaterials printed (Video S1). A $10 \mathrm{~cm}$ petri dish was used as the printing surface to provide better visibility between the nozzle tip and the printing surface during the calibration phase. The scaffolds were printed on $16 \mathrm{~mm}$ coverslips which were placed radially into the $10 \mathrm{~cm}$ petri dish. After printing, the scaffolds were treated with $1 \mathrm{~mL}$ of crosslinking solution $\left(90 \mathrm{mM} \mathrm{CaCl}_{2}\right.$, Cellink, Sweden) for $2 \mathrm{~min}$. 
Table 1. The parameters used for each printhead during bioprinting. Printheads 1 and 2 were used for the hydrogel layers, while printhead 3 was used to print the outer frame of PCL (RT: room temperature).

\begin{tabular}{cccccc}
\hline Title 1 & Material & Nozzle Size & Temperature & Pressure & Speed \\
\hline Printhead 1 & Hydrogel (deep zone) & $0.2 \mathrm{~mm}$ & RT & $14 \mathrm{kPa}$ & $12 \mathrm{~mm} / \mathrm{s}$ \\
Printhead 2 & Hydrogel (superficial and middle zones) & $0.2 \mathrm{~mm}$ & RT & $14 \mathrm{kPa}$ & $12 \mathrm{~mm} / \mathrm{s}$ \\
Printhead 3 & PCL & $0.2 \mathrm{~mm}$ & $210{ }^{\circ} \mathrm{C}$ & $200 \mathrm{kPa}$ & $4 \mathrm{~mm} / \mathrm{s}(\mathrm{base})$ \\
& & & & & \\
\hline
\end{tabular}

\subsection{In Vitro Culture}

The bioprinted constructs were cultured in chondrocyte differentiation basal medium (CloneticsTM CDMTM BulletKitTM, Lonza, Delft, The Netherlands) containing FBS, insulin, R3-IGF-1, gentamicin/amphotericin B, transforming growth factor- $\beta 1$, and transferrin (undisclosed concentrations by Lonza). The differentiation medium was further enriched with $10 \mathrm{ng} / \mathrm{mL}$ fresh transforming growth factor- $\beta 3$ (SRP3171, Sigma, Delft, The Netherlands) and $70 \mathrm{mM}$ L-ascorbic acid 2-phosphate (A8960, Sigma, The Netherlands) for each medium change, according to the manufacturer's instructions (TS-CC-112-7 02/20, Lonza). The differentiation medium was changed three times a week for 25 days using $2 \mathrm{~mL}$ of medium per well (each well contained one scaffold), which was kept in a 24-well plate in an incubator at $37{ }^{\circ} \mathrm{C}, 90 \%$ humidity, and $5 \% \mathrm{CO}_{2}$. The experiment included three scaffolds per condition (graded, homogeneous) per timepoint (day 0 and day 25).

\subsection{Mechanical Characterization}

The 3D printed scaffolds (cell-free) were mechanically characterized using a uniaxial unconfined compression test using the LLOYD Instruments LR5k compression machine (AMETEK test \& calibration instruments). The PCL frame, hydrogel, and the combined scaffolds (PCL and hydrogel) were tested separately using a $100 \mathrm{~N}$ load cell with a $0.1 \mathrm{~N}$ preload, a $1 \mathrm{~mm}$ deflection, and a strain rate of $0.002 \mathrm{~s}^{-1}$ (i.e., a crosshead speed of $0.36 \mathrm{~mm} / \mathrm{min}$ ). From the load-deflection curve generated by the machine on the Nexygen software, 200 data points were exported per test for further analysis. Each of the data points included the recorded time (s), load $(\mathrm{N})$, crosshead travel $(\mathrm{mm})$, and deflection from the preload $(\mathrm{mm})$, which were used for the generation of the stress-strain curves and the calculation of the compressive stiffness of the scaffolds. The stress was calculated by dividing the compression force by the cross-section area, and the strain was defined as the ratio of the crosshead travel to the initial length of the specimens. The stiffness calculations were performed using a moving regression algorithm generated with Gnu R [22] that was used to calculate the linear line with the steepest slope fit of the stress-strain curve. The slope of the linear curve was taken as the value for the compressive stiffness of the scaffolds $(\mathrm{E}=\sigma / \varepsilon, \mathrm{MPa})$.

\subsection{Live/Dead Assay}

Cell viability was assessed at day 0 (post-printing) and day 25 after culture using live/dead staining (LIVE/DEAD ${ }^{\circledR}$ Viability/Cytotoxicity Kit, ThermoFisher, Delft, The Netherlands). Briefly, the samples were washed twice with $1 \times$ PBS for $5 \mathrm{~min}$ before supplementing the scaffolds with $2 \mathrm{mM}$ ethidium homodimer- 1 (red, for dead cells) and $5 \mathrm{mM}$ calcein-AM (green, for live cells) in $1 \times$ PBS. The samples were allowed to incubate for $1 \mathrm{~h}$ at $37^{\circ} \mathrm{C}$ before being washed twice in $1 \times \mathrm{PBS}$ and being imaged under a fluorescent microscope (ZOE fluorescent cell imager, Biorad, Delft, The Netherlands).

\subsection{Histology Staining}

All the specimens were fixed overnight in $4 \%$ paraformaldehyde at $4{ }^{\circ} \mathrm{C}$ with a tissuefixative volume ratio of 1:20. Next, the scaffolds were washed twice with PBS, and were placed in a 1:1 solution of 100\% EtOH:90 mM Cellink crosslinking agent (final $45 \mathrm{mM}$ $\mathrm{CaCl}$ ) for storage. The samples were paraffin-embedded and were sectioned at a thickness 
of $6 \mu \mathrm{m}$. The sections were stained with hematoxylin (HHS32, Sigma, The Netherlands) and eosin (HT110232, Sigma, The Netherlands) to examine their cell distribution, with $1 \%$ Alcian Blue (TMS-010-C, Sigma, The Netherlands) to analyze their sGAG content, and with Picrosirius Red (365548, Sigma, The Netherlands) for collagen deposition. The stained histological slices were imaged under a DM500 optical Leica microscope.

\subsection{Image Analysis}

The histological images were analyzed for the cell density in each of the three zones, as well as for the neo-tissue formation (sGAG and collagen deposition) within the hydrogel for all three zones. The analysis of the data was performed using Image J v2.0.0 software. The images were spatially calibrated using their integrated scale bar. For the analysis of H\&E staining, the microscopic images were first split into the three-color channels RGB. Then, the green channel was selected as the optimum channel for the identification of the nuclei. Next, the threshold was adjusted before using the "analyze particles" plugin. The minimum size was set between five and 35 pixels depending on the image, while the maximum size was set at 300 pixels. The circularity range was set between 0.45 and 1.00 for all the images. This analysis of the H\&E images was performed using the ROI (region of interest) manager to select three regions of interest corresponding to the three different zones and to analyze them separately using a different threshold and size spectrum depending on their specific data. For the samples stained with Alcian Blue and Picrosirius Red, the image analysis was performed with the use of the Trainable Weka Segmentation plugin [23]. This plugin utilizes a segmentation algorithm that combines a collection of machine learning algorithms with a set of selected image features to produce pixel-based segmentations. Three classes were used for the training of the algorithm and the classification of the results: (a) a class for the negative background staining of the alginate, (b) a class for the stained cell nuclei, and (c) a class for the positively stained areas (areas with darker blue or red color for $\mathrm{AB}$ and PR, respectively). The training of the algorithm was performed by manually selecting multiple areas belonging to each of the classes using the Image J's selection tool and categorizing them according to their corresponding class. After that, the features of the input image were extracted and converted to a set of vectors of float values (format for Weka classifiers). Finally, the plugin created and displayed the resulting image. This image was equivalent to the current overlay ( 8 bit color with each color corresponding to a specific class). The training features used for the training of the algorithm were Gaussian blur, Sobel filter, Hessian matrix, and the difference of the Gaussians. After training, the same classifier was applied to all the images of the same staining. The plugin performed the image segmentation on the basis of the current classifier and the selected features and created a stack of images, each one highlighting one of the selected features. By selecting the desired 8 bit color image from the stack and setting an appropriate threshold, we performed area measurements on the objects within the images to evaluate the sGAG content of the areas positively stained for collagen (for all the zones and timepoints). The ratio between positive area and total area for the samples analyzed is presented as a percentage.

\subsection{Statistical Analysis}

All quantitative results are presented as the mean \pm standard deviation. Statistical analysis was performed using GraphPad Prism 8 (GraphPad Software, San Diego, CA, USA, Version 8.0.2). For the analysis of the cell density, sGAG content, and collagen content, the experimental groups were analyzed for significant differences using a two-way analysis of variance (ANOVA) and the results were corrected for multiple comparisons using Bonferroni's post hoc test. For the comparison of the stiffness, as well as for the differences in the cell viability and cell density between the two different scaffold designs, an unpaired $t$-test or one-way ANOVA was performed. Probability $p$-values $<0.05$ were considered statistically significant. 


\section{Results}

3.1. PCL-Reinforced Alginate Scaffolds with Different Cell Density Zones Can Be Successfully Fabricated as Single Units Using Bioprinting

Firstly, we designed a structure that could combine both an outer frame of stiff PCL and the soft alginate-based bioink with an overall size of $8 \mathrm{~mm} \times 8 \mathrm{~mm} \times 3 \mathrm{~mm}$ (Figure 2a-c). For the PCL frame, two different designs were tested: a closed design (Figure S1a) and an open design (Figure 2a and Figure S1b). The open design resulted in a higher viability of the cells in the bioink (Figure S1c-e) and was, therefore, chosen for further experiments. For the bioink, a 10\% infill density was selected in order to create channels in the $z$-direction (Figure 2e) that resulted in visible pores in the scaffold of $\sim 0.230 \mathrm{~mm}^{2}$ (Figure 2c) to allow for sufficient nutrient diffusion to all the layers of the cell-laden hydrogel. The different parts of the zonal scaffold showing the PCL frame in yellow and the three different cell density zones in red were sliced into a printing pattern suitable for 3D printing (Figure 2d). The design used for the fabrication of the biomimetic cartilage scaffolds was bioprinted monolithically as a single unit (Figure 2e). The mean compressive stiffness of the scaffolds (PCL + hydrogel) was $8.35 \pm 0.43 \mathrm{MPa}$. This was mostly attributed to the PCL framework, since the mean compressive stiffness of the PCL framework alone was $8.02 \pm 0.69 \mathrm{MPa}$ while the hydrogel alone was $0.23 \mathrm{MPa} \pm 0.01$ (Figure 2f).

The next step was to verify that we could 3D print the different zones (top, middle, and bottom) with different cell densities of human chondrocytes (i.e., $20 \times 10^{6}, 10 \times 10^{6}$, and $5 \times 10^{6}$ cells $/ \mathrm{mL}$, respectively), recapitulating some aspects of the cytocomplexity of the human hyaline articular cartilage. Live/dead staining at day 0 post bioprinting demonstrated that it was possible to control such cell distribution, as evidenced by a higher cell density in the top zone and the lowest cell density in the bottom zone (Figure $2 \mathrm{~g}$ ). Overall, a high viability ( $>90 \%$ ) of the bioprinted cells was observed throughout the different zones of the scaffolds (Figure $2 \mathrm{~h}$ ).

\subsection{Cell Density Can Be Maintained in the Different Zones Overtime In Vitro}

To investigate the maintenance of the zonal distribution of the cells over time, we cultured human chondrocytes in the hydrogel for 25 days. We compared the scaffolds with different cell densities, herein called the zonal scaffolds, with the scaffolds in which the cell density (10E6 cells $/ \mathrm{mL}$ ) was constant throughout the entire scaffold. At day 0 , right after the bioprinting process took place, a high cell viability was detected for the embedded cells (Figure 3a). In addition, the quantification of the H\&E staining at day 0 showed significant differences between the bottom/middle, middle/top, and bottom/top zones of the graded scaffolds (Figure 3b, left), whereas no difference in the cell density was observed throughout the homogeneous scaffolds (Figure 3b, right). After 25 days of culture, cell viability remained high for all the specimens (Figure 3c). In addition, a decrease in the cell density of the middle zone was observed, rendering the cell density between the middle and the bottom zones as not significantly different, while the cell density in the top zone remained significantly higher than the other zones (Figure 3d, left). The cell density of the homogeneous scaffolds remained constant throughout the scaffold thickness for all the timepoints (Figure 3d, right). 
(a)

$$
\text { PCL frame }
$$

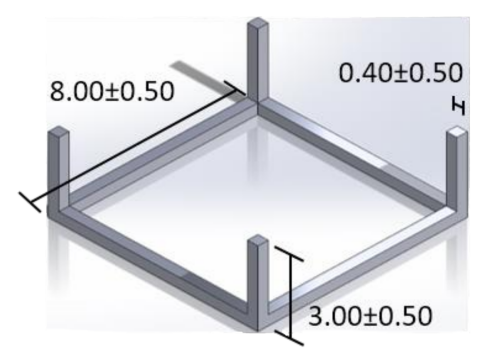

(d)

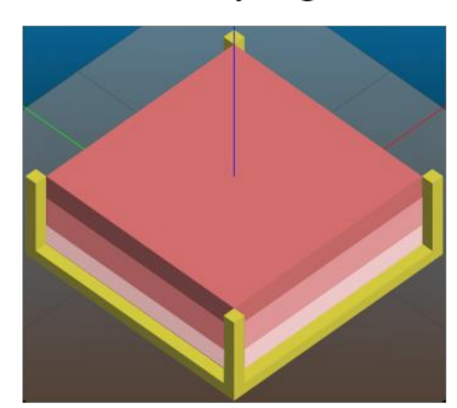

(g)

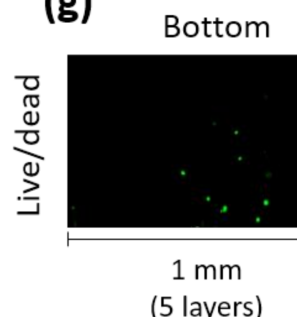

(b)

Hydrogel

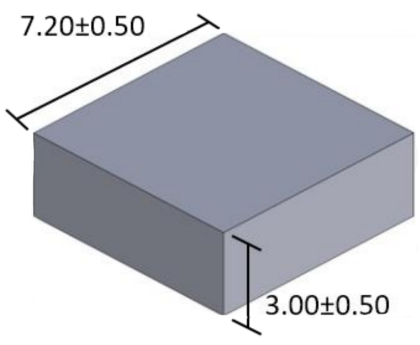

(e) slic3r printing pattern

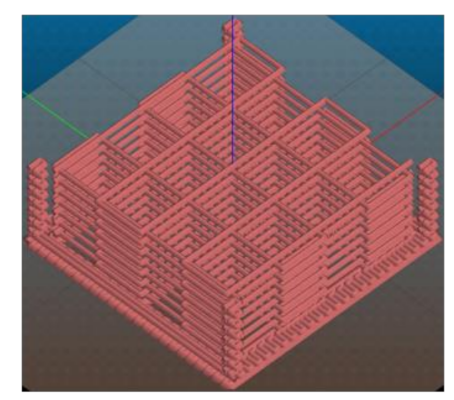

Middle

Top

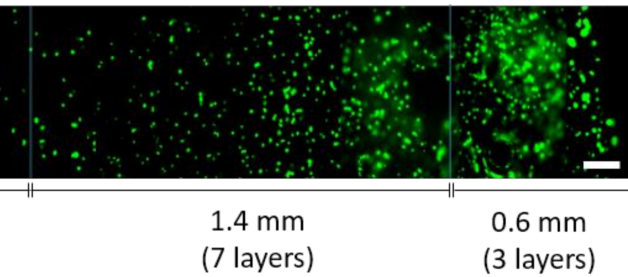

(c)

Macroscopic image

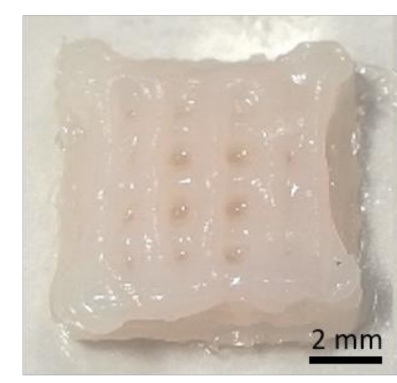

(f)

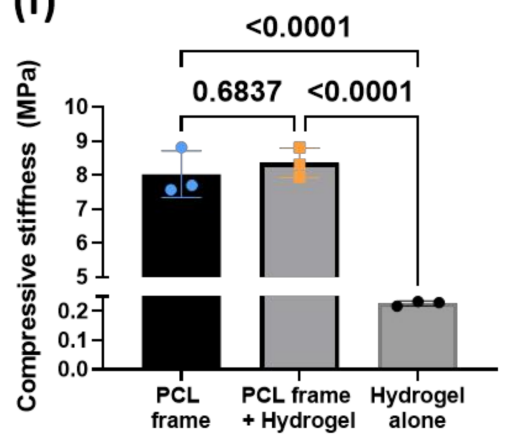

(h)

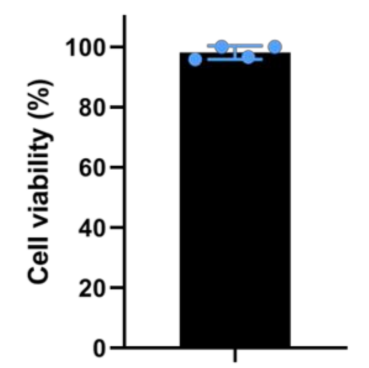

Figure 2. PCL-reinforced alginate scaffolds with different cell density zones can be bioprinted as a single unit. (a) The solid structure created in Solidworks corresponding to the outer PCL frame; (b) the solid structure corresponding to the hydrogel part; (c) a macroscopic image of the top view of a 3D printed scaffold after ionic crosslinking; (d) the different solid structures combined by Slic3r software, showing the PCL in yellow and the hydrogel in different shades of red for the different cell density zones; (e) Slic3r design of the printing pattern showing a 100\% infill for the PCL and a $10 \%$ infill for the hydrogel; (f) a bar chart showing the mechanical properties (stiffness) of the outer PCL frame, the combined PCL frame + hydrogel, and the hydrogel alone printed scaffolds $(n=3) ;(\mathrm{g})$ a fluorescent microscopic image of cell viability with live/dead staining (green: live; red: dead) showing the cell distribution in the scaffold bioprinted with three different cell densities for each of the zones: bottom $(5 \mathrm{E} 6 \mathrm{cell} / \mathrm{mL})$, middle $(10 \mathrm{E} 6$ cells $/ \mathrm{mL})$, and top $(20 \mathrm{E}$ cells $/ \mathrm{mL})$ at day 0 . Lines are drawn on the image to illustrate the approximate division of the zones. Scale bar $=200 \mu \mathrm{m}$; (h) the corresponding quantification of the overall live and dead cells $(n=4)$. 

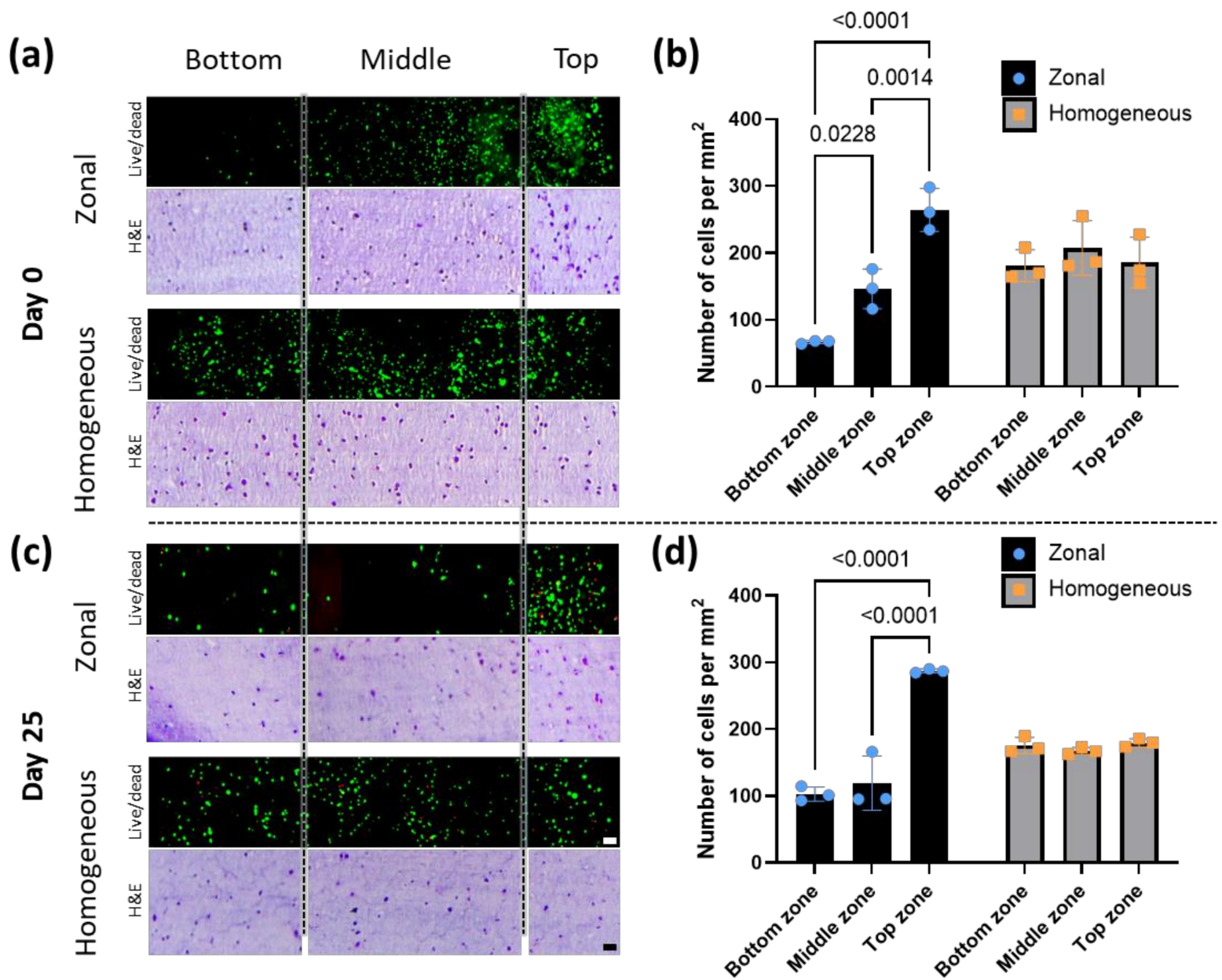

Figure 3. Gradient cell density can be maintained in the zonal scaffold over time in in vitro culture; (a) fluorescent microscopic images indicate cell viability based on live/dead staining (green: alive; red: dead) and bright-field microscopy images of the H\&E staining (matrix: violet; nuclei: dark purple) showing the cell distribution for the three different zones, bottom, middle, and top, of the zonal and homogeneous bioprinted scaffolds at day 0 ; (b) the quantification of the number of the cells from the H\&E staining at day $0 ;$ (c) the live/dead and H\&E images of the zonal and homogeneous scaffold at day 25; (d) the quantification of the number of cells from the H\&E staining at day 28 ( $n=3$; $p$-values $<0.05$ are shown). Scale bar: $100 \mu \mathrm{m}$.

\subsection{Bioprinted Zonal Scaffold with Different Cell Densities Leads to a Gradient Cell-Derived ECM Deposition}

The evaluation of the sGAG and collagen deposition in the bioprinted scaffolds was performed on the basis of the analysis of Alcian Blue and Picrosirius Red histological staining of the scaffold cross-sections. At day 0, the histological analysis showed the background staining for the basal bioink material (alginate and methylcellulose) with a weak staining for Alcian Blue (Figure 4a) and a strong pink (negative for collagen) staining for Picrosirius Red (Figure 4c). A semiquantitative analysis of the stained samples was performed using an optimized threshold to subtract the background staining from positively stained areas (Figure $4 b, d$ ). 

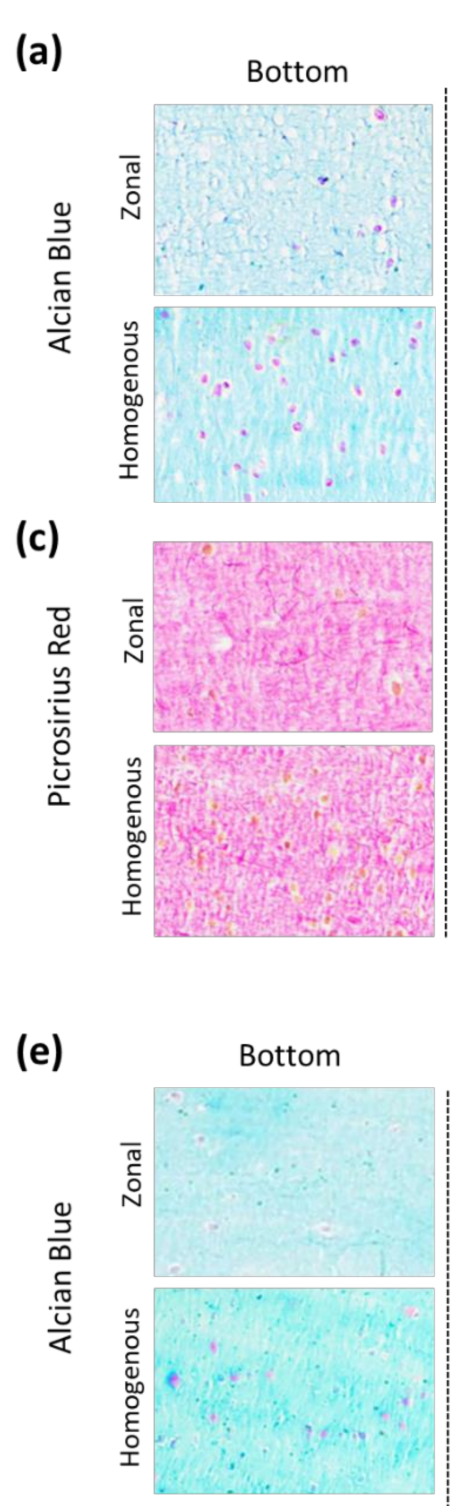

(g)

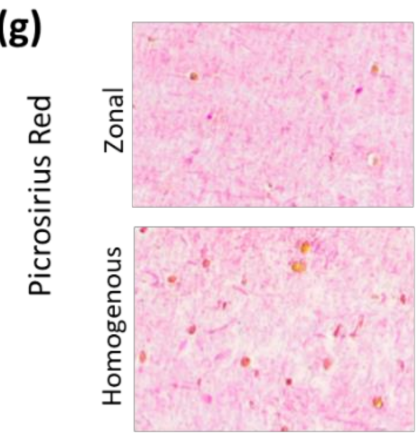

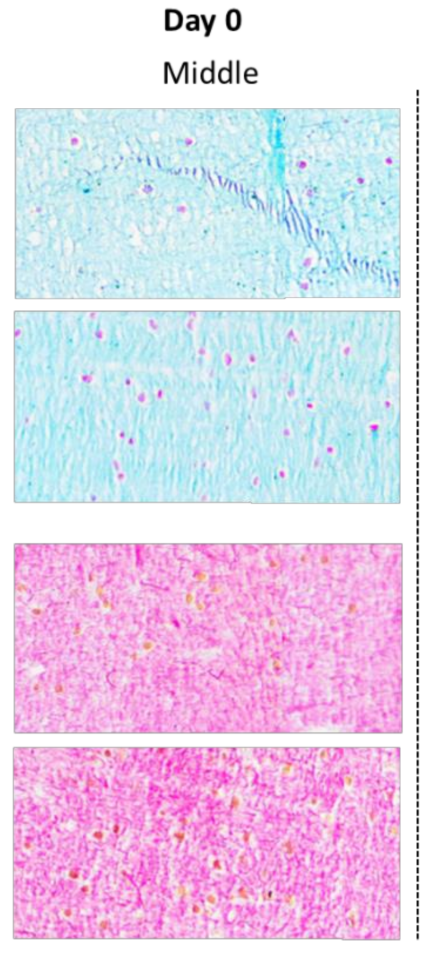

Day 25

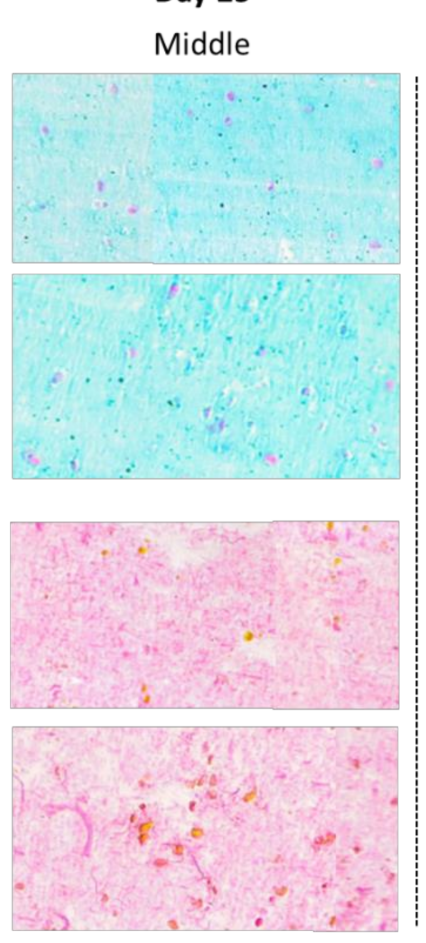

Top

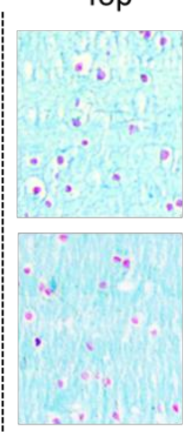

(b)

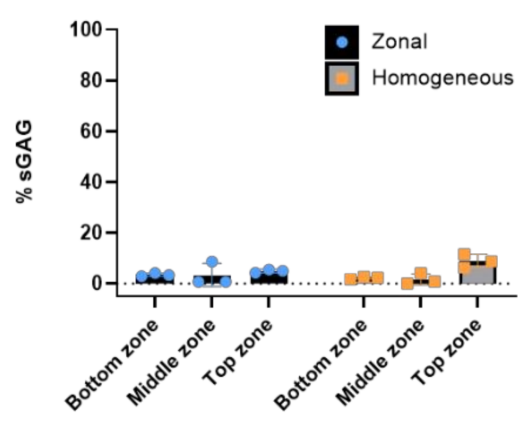

(d)
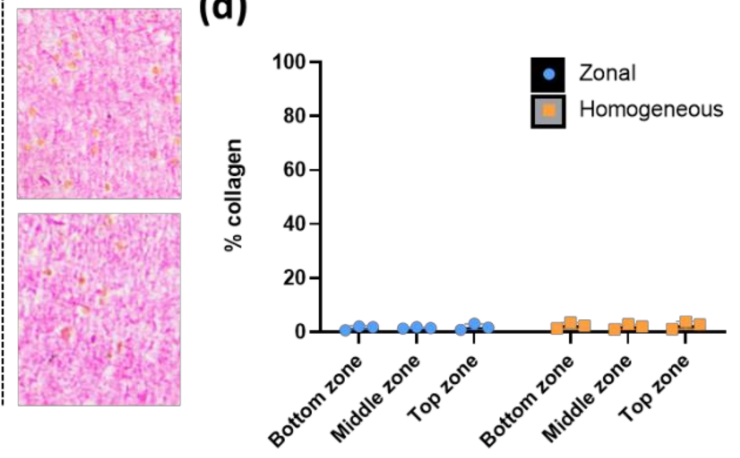

Top
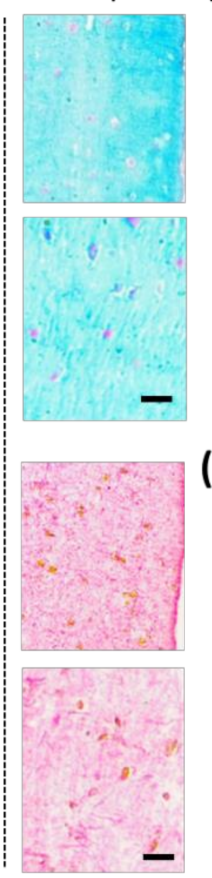

(f)

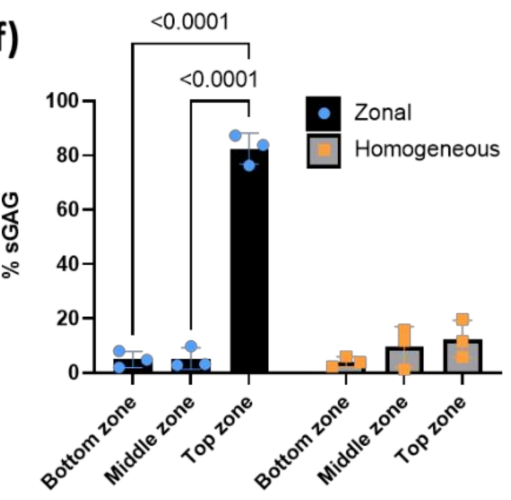

(h)

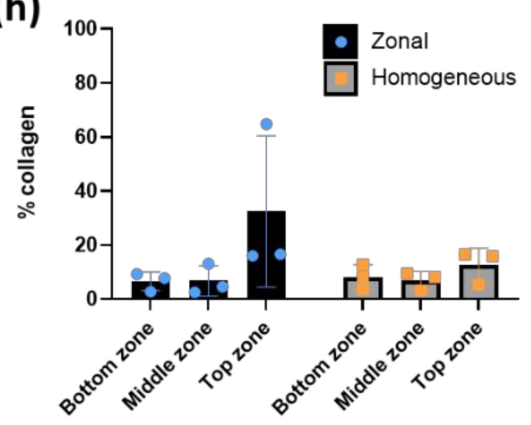

Figure 4. Bioprinted zonal scaffolds with cell density gradients result in differential cartilage-like tissue deposition; (a) histological images of zonal or homogeneous scaffold bioprinted with human chondrocytes and evaluated for sGAG with Alcian Blue staining (AB) at day 0; (b) the corresponding semiquantitative zonal analysis of the AB staining; (c) histological images evaluated for collagen deposition with Picrosirius Red staining (PSR) at day 0; (d) the corresponding semiquantitative zonal analysis of the PSR staining; (e) the histological images evaluated for sGAG with AB after 25 days in culture; (f) the corresponding semiquantitative zonal analysis of the AB staining; (g) histological images evaluated for collagen with PSR; (h) the corresponding semiquantitative zonal analysis of the PSR staining ( $n=3$; $p$-values $<0.05$ are shown). Scale bar: $100 \mu \mathrm{m}$. 
At day 25 of culture, both types of staining demonstrated that the scaffolds supported the deposition of cartilage-like tissue components. In the zonal scaffold, Alcian Blue staining revealed an increased deposition of SGAG in the top zone of the scaffold at day 25, as indicated by a strong Alcian Blue signal (Figure 4e, zonal, AB, top). The semiquantification of the staining revealed the zonal manner in which sGAG was deposited within the scaffolds over time, displaying a significantly increase from the bottom to the top zone (Figure $4 \mathrm{f}$, left), which was in accordance with the cell density distribution within the scaffolds. The homogeneous scaffolds deposited a similar amount of sGAG in all the different zones at day 25 (Figure 4e, homogeneous, AB and Figure $3 \mathrm{f}$, right). For the collagen deposition, it was observed that chondrocytes appeared to mainly secrete small amounts of pericellular collagen according to the intense orange-red staining observed (which is positive for collagen staining) after 25 days of culture (Figure $4 \mathrm{~g}$ ). Similar to the result of Alcian Blue staining, some samples exhibited a trend toward stronger staining in the top zone of the specimens. By comparison, the homogeneous scaffolds revealed no differences in their staining throughout the section. The statistical analysis of the semiquantitative values corresponding to Picrosirius Red revealed a trend of increasing collagen deposition in the top zone of some of the zonal scaffolds. However, no significant differences were found between the groups after 25 days of culture (Figure $4 \mathrm{~h}$ ).

\section{Discussion}

In this study, we aimed to generate a cartilage scaffold of a clinically relevant size that mimics the gradient distribution of cells that is observed across the three distinct zones of the native tissue in hyaline articular cartilage of the human condyle and to analyze the cell viability and cell-derived matrix deposition. Over time in culture, the generated zonal scaffolds led to a gradient in cartilage-like matrix deposition. For printing each zonal scaffold, four different inks (one ink and three bioinks) were used to print different parts of the scaffold. Every printing part used its own printhead except for the middle and top zones where the bioink-containing cartridge had to be interchanged for every printed scaffold. This allowed us to simultaneously 3D print a PCL frame and the different chondrocyte-embedded zones with clinically relevant thicknesses and zone-specific cell densities. Few papers have investigated the 3D printing of more than one bioink for a single construct $[10,19,24-26]$, probably due to the lack of several printheads or impracticality due to the constant changing of the printing cartridges that results in a time-consuming process. Recent studies suggest the use of coaxial needles [27] or continuous chaotic printing [28] as alternatives to generate multicellular heterogeneous systems. Several studies have combined PCL with bioinks to enhance the compressive stiffness of hydrogels [29-31]. In our study, the PCL frame helped the maintenance of the structural integrity of the scaffolds during bioprinting and subsequent in vitro culture. In addition, a PCL frame can be useful for future in vivo implantation [32,33]. Previous studies have shown that different cell densities can lead to different mechanical properties which are correlated with the amount of sGAG produced. In this study, we did not perform mechanical characterization of the hydrogel overtime. Therefore, future studies should also focus on the effect of different cell densities on the mechanical properties of the scaffold overtime. Regarding the PCL reinforcement, in most studies, this reinforcement is done by printing a mesh of PCL fibers in between hydrogel fibers, where the fiber orientation alternates orthogonally after every layer. In this study, however, it was determined that passing the hot $\left(210^{\circ} \mathrm{C}\right)$ thermoplastic nozzle right next to the cell-embedded hydrogel fibers negatively affects the chondrocyte viability, which has been also noted in other studies [34]. Therefore, another design approach was chosen in which the PCL would act as an outer skeleton for the hydrogel, concentrating the cell-embedded volume of the bioink at the center and maintaining its shape throughout its thickness. This approach was able to significantly increase the bulk mechanical properties compared to the bioink alone, as others have demonstrated [29-31]. Other studies also explored the pre-printing of PCL structures and then either cast or z-printed the bioink in the channels of the PCL mesh [35]. Despite 
this option giving more freedom, as it decouples the fabrication process of the outer frame and the bioprinting of the bioink, z-print is not yet an option available in all 3D printing systems. After fabrication of such complex structures, live/dead and histological analysis demonstrated that human chondrocytes still retained high viability and zonespecific cell densities. In addition, this cell density gradient was shown to be maintained during in vitro culture for 25 days, resulting in a gradient in tissue deposition as compared to homogeneous scaffolds. Previous studies aiming to fabricate similar constructs with different cell density layers through bioprinting have not shown such clear cell distribution or its maintenance over time [19]. For example, it has been reported that cell gradient in scaffolds of $3 \mathrm{~mm}$ thickness fail due to the fusion of the zones during bioprinting. Moreover, the analysis of that study was focused on the overall scaffold rather than on the individual zones [19]. It is noteworthy that the difference in cell number between the middle and the bottom zones in the gradient scaffold is less apparent after culture in differentiation medium. Although cells do not tend to migrate in alginate, this particular bioink formulation containing methylcellulose may allow for some cellular migration [36] from the middle to the bottom layer, perhaps in the search for available nutrients and oxygen. This potential migration may have been caused by the cell gradient itself, as no changes in cell number were observed in the homogeneous scaffold. Further research is needed to verify this hypothesis. Despite the presence of the tissue deposition gradients, low amounts of glycosaminoglycan and collagen were seen in all the groups. This may be due to the alginate-based bioinks that offer good printability [25,30,35,37-41] but do not offer enzymatic-derived tissue remodeling [42], which have been suggested to potentially act as a physical barrier for tissue secretion in vitro, as also observed by others [43-45]. On the other hand, alginate-based biomaterials have been shown to be capable of generating cartilage when implanted in vivo [46,47], suggesting that other factors may also be playing a role in this regard. For instance, chondrocytes from only one donor were used in our study, and it is known that there can be some variability between donors or even between chondrocytes from different zones [45]. Regarding tissue deposition, it is interesting to point out that the superficial zone of native mature articular cartilage is characterized by a lower sGAG presence than the other zones. Our scaffold demonstrated that having a higher cell density in the superficial zone will result in higher sGAG. However, the tissue formed in our scaffold is still in development and yet far from what is seen in articular cartilage tissue. It will be necessary to evaluate how applications of these different zones would influence eventual tissue that is formed using in vivo models. Our study is in agreement with the previous studies showing that constructs with a higher cell density result in higher cartilage-like matrix deposition $[48,49]$ and enhanced gene expression of cartilage markers [19]. This study focused on the recapitulation of the cell gradient observed in native hyaline articular cartilage. However, there are other gradients that could be interesting to investigate or even to combine. For instance, AC has been shown to have a gradient in stiffness [50-53]. Previous research has aimed to combine a stiffness gradient achieved by photo-crosslinking with a growth factor gradient achieved by mixing both TGF- $\beta 1$ and BMP-2 in the hydrogel (before crosslinking). These gradients proved capable of regulating the number of embedded hMSCs and their differentiation toward bone- or cartilage-like matrix-producing cells [18]. In addition, from a developmental biology perspective, cartilage starts as a soft template. Therefore, it may be interesting to explore the generation of the stiffness gradients that occur in time. This points to the need for the development of new $4 \mathrm{D}$ bioprinting approaches that investigate the use of stimulus-responsive biomaterials to answer such complex questions [54].

\section{Conclusions}

In this study, zonal cartilage scaffolds with clinically relevant sizes and cell densities were successfully bioprinted as single units. The different zonal cell densities were partially maintained in vitro for 25 days. In addition, the scaffolds led to a gradient in the extracellular matrix components produced by the embedded human chondrocytes. These findings 
shed some light on the effects of zonal cell gradients on the formation of new tissue matrix and help in addressing the remaining obstacles in order to accelerate the translation of cartilage tissue engineering into clinical practice.

Supplementary Materials: The following are available online at https://www.mdpi.com/article/ 10.3390/app11177821/s1: Figure S1. PCL design can affect cell viability; Video S1. A clip of the bioprinting process.

Author Contributions: Conceptualization, A.D., R.N., L.E.F.-A. and A.A.Z.; methodology, P.J.D.-P., A.D., M.M., M.H. and N.K.; software, P.J.D.-P. and A.D.; formal analysis, P.J.D.-P. and A.D.; investigation, P.J.D.-P. and A.D.; writing —original draft preparation, P.J.D.-P. and A.D.; writing-review and editing, P.J.D.-P., G.J.V.M.v.O., L.E.F.-A. and A.A.Z.; supervision, P.J.D.-P., M.N.-G., M.J.M. and L.E.F.-A.; project administration, L.E.F.-A. and A.A.Z.; funding acquisition, G.J.V.M.v.O. and A.A.Z. All authors have read and agreed to the published version of the manuscript.

Funding: This research was funded by the Dutch Medical Delta project: RegMed4D.

Data Availability Statement: The data that support the findings of this study are available from the corresponding author, [A.A.Z.], upon reasonable request.

Conflicts of Interest: The authors declare no conflict of interest.

\section{References}

1. Myers, K.R.; Sgaglione, N.A.; Grande, D.A. Trends in biological joint resurfacing. Bone Jt. Res. 2013, 2, 193-199. [CrossRef] [PubMed]

2. Brittberg, M.; Lindahl, A.; Nilsson, A.; Ohlsson, C.; Isaksson, O.; Peterson, L. Treatment of deep cartilage defects in the knee with autologous chondrocyte transplantation. N. Engl. J. Med. 1994, 331, 889-895. [CrossRef]

3. Ahern, B.; Parvizi, J.; Boston, R.; Schaer, T. Preclinical animal models in single site cartilage defect testing: A systematic review. Osteoarthr. Cartil. 2009, 17, 705-713. [CrossRef] [PubMed]

4. James, S.L.; Abate, D.; Abate, K.H.; Abay, S.M.; Abbafati, C.; Abbasi, N.; Abbastabar, H.; Abd-Allah, F.; Abdela, J.; Abdelalim, A.; et al. Global, regional, and national incidence, prevalence, and years lived with disability for 354 diseases and injuries for 195 countries and territories, 1990-2017: A systematic analysis for the global burden of disease study 2017. Lancet 2018, 392, 1789-1858. [CrossRef]

5. Roseti, L.; Grigolo, B. Host environment: Scaffolds and signaling (tissue engineering) articular cartilage regeneration: Cells, scaffolds, and growth factors. In Bio-Orthopaedics: A New Approach; Springer: Berlin/Heidelberg, Germany, 2017 ; pp. 87-103. ISBN 9783662541814.

6. Kreuz, P.; Steinwachs, M.; Erggelet, C.; Krause, S.; Konrad, G.; Uhl, M.; Südkamp, N. Results after microfracture of full-thickness chondral defects in different compartments in the knee. Osteoarthr. Cartil. 2006, 14, 1119-1125. [CrossRef]

7. Ansari, S.; Khorshidi, S.; Karkhaneh, A. Engineering of gradient osteochondral tissue: From nature to lab. Acta Biomater. 2019, 87, 41-54. [CrossRef] [PubMed]

8. Huber, M.; Trattnig, S.; Lintner, F. Anatomy, biochemistry, and physiology of articular cartilage. Investig. Radiol. 2000, 35, 573-580. [CrossRef]

9. Bracaglia, L.G.; Smith, B.T.; Watson, E.; Arumugasaamy, N.; Mikos, A.G.; Fisher, J.P. 3D printing for the design and fabrication of polymer-based gradient scaffolds. Acta Biomater. 2017, 56, 3-13. [CrossRef] [PubMed]

10. Levato, R.; Webb, W.; Otto, I.A.; Mensinga, A.; Zhang, Y.; van Rijen, M.; van Weeren, R.; Khan, I.; Malda, J. The bio in the ink: Cartilage regeneration with bioprintable hydrogels and articular cartilage-derived progenitor cells. Acta Biomater. 2017, 61, 41-53. [CrossRef]

11. Parisi, C.; Salvatore, L.; Veschini, L.; Serra, M.P.; Hobbs, C.; Madaghiele, M.; Sannino, A.; Di Silvio, L. Biomimetic gradient scaffold of collagen-hydroxyapatite for osteochondral regeneration. J. Tissue Eng. 2020, 11, 11. [CrossRef]

12. Liu, E.; Zhu, D.; Diaz, E.C.G.; Tong, X.; Yang, F. Gradient hydrogels for optimizing niche cues to enhance cell-based cartilage regeneration. Tissue Eng. Part A 2020, 27, 929-939. [CrossRef] [PubMed]

13. Gao, F.; Xu, Z.; Liang, Q.; Liu, B.; Li, H.; Wu, Y.; Zhang, Y.; Lin, Z.; Wu, M.; Ruan, C.; et al. Direct 3D printing of high strength biohybrid gradient hydrogel scaffolds for efficient repair of osteochondral defect. Adv. Funct. Mater. 2018, 28, 1706644. [CrossRef]

14. Chen, L.; Deng, C.; Li, J.; Yao, Q.; Chang, J.; Wang, L.; Wu, C. 3D printing of a lithium-calcium-silicate crystal bioscaffold with dual bioactivities for osteochondral interface reconstruction. Biomaterials 2019, 196, 138-150. [CrossRef] [PubMed]

15. Zhu, D.; Tong, X.; Trinh, P.; Yang, F. Mimicking cartilage tissue zonal organization by engineering tissue-scale gradient hydrogels as 3D cell niche. Tissue Eng. Part A 2018, 24, 1-10. [CrossRef]

16. Sun, Y.; You, Y.; Jiang, W.; Wang, B.; Wu, Q.; Dai, K. 3D bioprinting dual-factor releasing and gradient-structured constructs ready to implant for anisotropic cartilage regeneration. Sci. Adv. 2020, 6, eaay1422. [CrossRef]

17. Nowicki, M.A.; Castro, N.J.; Plesniak, M.W.; Zhang, L.G. 3D printing of novel osteochondral scaffolds with graded microstructure. Nanotechnology 2016, 27, 414001. [CrossRef] 
18. Jeon, O.; Alt, D.S.; Linderman, S.; Alsberg, E. Biochemical and physical signal gradients in hydrogels to control stem cell behavior. Adv. Mater. 2013, 25, 6366-6372. [CrossRef]

19. Ren, X.; Wang, F.; Chen, C.; Gong, X.; Yin, L.; Yang, L. Engineering zonal cartilage through bioprinting collagen type II hydrogel constructs with biomimetic chondrocyte density gradient. BMC Musculoskelet. Disord. 2016, 17, 1-10. [CrossRef] [PubMed]

20. Slic3r. Slic3r-Open Source 3D Printing Toolbox. Available online: https:/ / slic3r.org/ (accessed on 6 July 2021).

21. Hunziker, E.; Quinn, T.; Häuselmann, H.-J. Quantitative structural organization of normal adult human articular cartilage. Osteoarthr. Cartil. 2002, 10, 564-572. [CrossRef]

22. R Core Team. R: A Language and Environment for Statistical Computing; R Foundation for Statistical Computing: Vienna, Austria, 2018. Available online: https:/ / www.R-project.org (accessed on 20 August 2019).

23. Arganda-Carreras, I.; Kaynig, V.; Rueden, C.; Eliceiri, K.; Schindelin, J.E.; Cardona, A.; Seung, H.S. Trainable weka segmentation: A machine learning tool for microscopy pixel classification. Bioinformatics 2017, 33, 2424-2426. [CrossRef] [PubMed]

24. Li, C.; Faulkner-Jones, A.; Dun, A.R.; Jin, J.; Chen, P.; Xing, Y.; Yang, Z.; Li, Z.; Shu, W.; Liu, D.; et al. Rapid formation of a supramolecular polypeptide-DNA hydrogel for in situ three-dimensional multilayer bioprinting. Angew. Chem. Int. Ed. 2015, 54, 3957-3961. [CrossRef] [PubMed]

25. Li, H.; Tan, Y.J.; Leong, K.F.; Li, L. 3D bioprinting of highly thixotropic alginate/methylcellulose hydrogel with strong interface bonding. ACS Appl. Mater. Interfaces 2017, 9, 20086-20097. [CrossRef]

26. Kolesky, D.B.; Homan, K.A.; Skylar-Scott, M.A.; Lewis, J.A. Three-dimensional bioprinting of thick vascularized tissues. Proc. Natl. Acad. Sci. USA 2016, 113, 3179-3184. [CrossRef] [PubMed]

27. Dai, X.; Liu, L.; Ouyang, J.; Xingliang, D.; Zhang, X.; Lan, Q.; Xu, T. Coaxial 3D bioprinting of self-assembled multicellular heterogeneous tumor fibers. Sci. Rep. 2017, 7, 1-11. [CrossRef] [PubMed]

28. Chávez-Madero, C.; De León-Derby, M.D.; Samandari, M.; Ceballos-González, C.F.; Bolívar, E.; Mendoza-Buenrostro, C.C.; Holmberg, S.; Garza-Flores, N.A.; Almajhadi, M.A.; González-Gamboa, I.; et al. Using chaotic advection for facile highthroughput fabrication of ordered multilayer micro- and nanostructures: Continuous chaotic printing. Biofabrication 2020, 12, 035023. [CrossRef]

29. Lee, J.-S.; Hong, J.M.; Jung, J.W.; Shim, J.-H.; Oh, J.-H.; Cho, D.-W. 3D printing of composite tissue with complex shape applied to ear regeneration. Biofabrication 2014, 6, 024103. [CrossRef] [PubMed]

30. Daly, A.; Critchley, S.E.; Rencsok, E.M.; Kelly, D.J. A comparison of different bioinks for 3D bioprinting of fibrocartilage and hyaline cartilage. Biofabrication 2016, 8, 045002. [CrossRef] [PubMed]

31. Castilho, M.; Hochleitner, G.; Wilson, W.; Van Rietbergen, B.; Dalton, P.D.; Groll, J.; Malda, J.; Ito, K. Mechanical behavior of a soft hydrogel reinforced with three-dimensional printed microfibre scaffolds. Sci. Rep. 2018, 8, 1-10. [CrossRef] [PubMed]

32. Freeman, F.; Browe, D.; Nulty, J.; Von Euw, S.; Grayson, W.L.; Kelly, D.J. Biofabrication of multiscale bone extracellular matrix scaffolds for bone tissue engineering. Eur. Cells Mater. 2019, 38, 168-187. [CrossRef]

33. Critchley, S.; Sheehy, E.; Cunniffe, G.; Diaz-Payno, P.; Carroll, S.F.; Jeon, O.; Alsberg, E.; Brama, P.A.; Kelly, D.J. 3D printing of fibre-reinforced cartilaginous templates for the regeneration of osteochondral defects. Acta Biomater. 2020, 113, 130-143. [CrossRef]

34. Schuurman, W.; Khristov, V.; Pot, M.W.; van Weeren, P.R.; Dhert, W.J.A.; Malda, J. Bioprinting of hybrid tissue constructs with tailorable mechanical properties. Biofabrication 2011, 3, 021001. [CrossRef]

35. Schipani, R.; Scheurer, S.; Florentin, R.; Critchley, S.E.; Kelly, D.J. Reinforcing interpenetrating network hydrogels with 3D printed polymer networks to engineer cartilage mimetic composites. Biofabrication 2020, 12, 035011. [CrossRef]

36. Garrett, Q.; Simmons, P.A.; Xu, S.; Vehige, J.; Zhao, Z.; Ehrmann, K.; Willcox, M. Carboxymethylcellulose binds to human corneal epithelial cells and is a modulator of corneal epithelial wound healing. Investig. Ophthalmol. Vis. Sci. 2007, 48, 1559-1567. [CrossRef]

37. Yang, X.; Lu, Z.; Wu, H.; Li, W.; Zheng, L.; Zhao, J. Collagen-alginate as bioink for three-dimensional (3D) cell printing based cartilage tissue engineering. Mater. Sci. Eng. C 2018, 83, 195-201. [CrossRef]

38. Ávila, H.M.; Schwarz, S.; Rotter, N.; Gatenholm, P. 3D bioprinting of human chondrocyte-laden nanocellulose hydrogels for patient-specific auricular cartilage regeneration. Bioprinting 2016, 1-2, 22-35. [CrossRef]

39. Bendtsen, S.T.; Quinnell, S.P.; Wei, M. Development of a novel alginate-polyvinyl alcohol-hydroxyapatite hydrogel for 3D bioprinting bone tissue engineered scaffolds. J. Biomed. Mater. Res. Part A 2017, 105, 1457-1468. [CrossRef] [PubMed]

40. Markstedt, K.; Mantas, A.; Tournier, I.; Ávila, H.M.; Hägg, D.; Gatenholm, P. 3D bioprinting human chondrocytes with Nanocellulose-Alginate bioink for cartilage tissue engineering applications. Biomacromolecules 2015, 16, 1489-1496. [CrossRef] [PubMed]

41. de Melo, B.A.G.; Jodat, Y.A.; Mehrotra, S.; Calabrese, M.; Kamperman, T.; Mandal, B.B.; Santana, M.H.A.; Alsberg, E.; Leijten, J.; Shin, S.R. 3D printed cartilage-like tissue constructs with spatially controlled mechanical properties. Adv. Funct. Mater. 2019, 29, 1906330. [CrossRef]

42. Lee, K.Y.; Mooney, D.J. Alginate: Properties and biomedical applications. Prog. Polym. Sci. 2012, 37, 106-126. [CrossRef]

43. Van Susante, J.L.C.; Buma, P.; Van Osch, G.J.; Versleyen, D.; Van Der Kraan, P.M.; Van Der Berg, W.B.; Homminga, G.N. Culture of chondrocytes in alginate and collagen carrier gels. Acta Orthop. Scand. 1995, 66, 549-556. [CrossRef] 
44. van Osch, G.J.; Berg, W.B.V.D.; Hunziker, E.B.; Häusselmann, H.J. Differential effects of IGF-1 ans TGF $\beta-2$ on the assembly of proteoglycans in pericellular and territorial matrix by cultured bovine articular chondrocytes. Osteoarthr. Cartil. 1998, 6, 187-195. [CrossRef] [PubMed]

45. Malda, J.; Hoope, W.T.; Schuurman, W.; Van Osch, G.J.; Van Weeren, P.R.; Dhert, W.J. Localization of the potential zonal marker clusterin in native cartilage and in tissue-engineered constructs. Tissue Eng. Part A 2010, 16, 897-904. [CrossRef] [PubMed]

46. Pleumeekers, M.M.; Nimeskern, L.; Koevoet, W.L.M.; Kops, N.; Poublon, R.M.L.; Stok, K.S.; Van Osch, G.J.V.M. The in vitro and in vivo capacity of culture-expanded human cells from several sources encapsulated in alginate to form cartilage. Eur. Cells Mater. 2014, 27, 264-280. [CrossRef]

47. Marijnissen, W.J.; van Osch, G.J.; Aigner, J.; van der Veen, S.W.; Hollander, A.P.; Verwoerd-Verhoef, H.L.; Verhaar, J. Alginate as a chondrocyte-delivery substance in combination with a non-woven scaffold for cartilage tissue engineering. Biomaterials 2002, 23, 1511-1517. [CrossRef]

48. Talukdar, S.; Nguyen, Q.T.; Chen, A.C.; Sah, R.L.; Kundu, S.C. Effect of initial cell seeding density on 3D-engineered silk fibroin scaffolds for articular cartilage tissue engineering. Biomaterials 2011, 32, 8927-8937. [CrossRef]

49. Mauck, R.; Wang, C.-B.; Oswald, E.; Ateshian, G.; Hung, C. The role of cell seeding density and nutrient supply for articular cartilage tissue engineering with deformational loading. Osteoarthr. Cartil. 2003, 11, 879-890. [CrossRef]

50. Moshtagh, P.R.; Pouran, B.; Korthagen, N.M.; Zadpoor, A.A.; Weinans, H. Guidelines for an optimized indentation protocol for measurement of cartilage stiffness: The effects of spatial variation and indentation parameters. J. Biomech. 2016, 49, 3602-3607. [CrossRef] [PubMed]

51. Ebenstein, D.; Kuo, A.; Rodrigo, J.J.; Reddi, A.H.; Ries, M.; Pruitt, L. A nanoindentation technique for functional evaluation of cartilage repair tissue. J. Mater. Res. 2004, 19, 273-281. [CrossRef]

52. Bae, W.C.; Lewis, C.W.; Levenston, M.; Sah, R.L. Indentation testing of human articular cartilage: Effects of probe tip geometry and indentation depth on intra-tissue strain. J. Biomech. 2006, 39, 1039-1047. [CrossRef] [PubMed]

53. Antons, J.; Marascio, M.G.M.; Nohava, J.; Martin, R.; Applegate, L.A.; Bourban, P.E.; Pioletti, D.P. Zone-dependent mechanical properties of human articular cartilage obtained by indentation measurements. J. Mater. Sci. Mater. Med. 2018, 29, 1-8. [CrossRef] [PubMed]

54. Wan, Z.; Zhang, P.; Liu, Y.; Lv, L.; Zhou, Y. Four-dimensional bioprinting: Current developments and applications in bone tissue engineering. Acta Biomater. 2020, 101, 26-42. [CrossRef] [PubMed] 